\title{
Endoscopic Transsphenoidal Approach for Surgical Treatment of Growth Hormone Secreting Pituitary Adenoma: Endocrinological Outcome in 49 Patients Based on 2010 Consensus Criteria for Remission - Preliminary Results
}

\author{
Mohammad Taghvaei, ${ }^{1,2}$ Seyed Mousa Sadrehosseini, ${ }^{3}$ Seyed Mojtaba Miri, ${ }^{1,2}$ and Mehdi \\ Zeinalizadeh ${ }^{1,2, *}$ \\ ${ }^{1}$ Brain and Spinal Injury Research Center (BASIR), Imam Khomeini Hospital Complex, Tehran University of Medical Sciences, Tehran, Iran \\ ${ }^{2}$ Department of Neurological Surgery, Imam Khomeini Hospital Complex, Tehran University of Medical Sciences, Tehran, Iran \\ ${ }^{3}$ Department of Otolaryngology-Head and Neck Surgery, Imam Khomeini Hospital Complex, Tehran University of Medical Sciences, Tehran, Iran \\ "Corresponding author: Mehdi Zeinalizadeh, Imam Khomeini Hospital Complex, Keshavarz Blvd, P. O. Box 1419733141, Tehran, IR Iran. Tel: +98-2161192637, Fax: +98-2166940033, \\ E-mail: mzeinalizadeh@tums.ac.ir
}

Received 2017 May 27; Accepted 2017 July 22.

\begin{abstract}
Background: Nowadays, the endoscopic transsphenoidal approach is the initial option for resection of all pituitary adenomas. The current study reported the experience with endoscopic transsphenoidal surgery remission rates using the 2010 consensus criteria, predictors of remission, and the associated complications.

Methods: A prospectively collected database of 49 patients with acromegaly who underwent endoscopic endonasal transsphenoidal surgery was analyzed. Tumors were classified according to size, as well as the Knosp and the Hardy-Wilson classifications. Endocrinological remission was defined as normal insulin-like growth factor (IGF)-I level and either a suppressed growth hormone $(\mathrm{GH})$ level $<0.4 \mathrm{ng} / \mathrm{mL}$ during an oral glucose tolerance test, or a random $\mathrm{GH}$ level $<1.0 \mathrm{ng} / \mathrm{mL}$ at least 3 months after the surgery. The extent of resection was evaluated on postoperative contrast-enhanced magnetic resonance imaging (MRI).

Results: Biochemical remission was achieved in 7 of $9(77.8 \%)$ microadenoma and 28 of 40 (70\%) macroadenoma. The total remission rate was $71.4 \%$ and gross total resection was achieved in 45 of 49 (91.8\%) patients. Tumor size, age, gender, history of prior surgery, suprasellar extension, and sphenoid sinus invasion were not associated with remission rate. Preoperative variables predictive of remission included the Knosp score $(\mathrm{P}=0.041)$ and $\mathrm{GH}$ levels $(\mathrm{P}=0.047)$. Two patients $(4.1 \%)$ experienced postoperative pan hypopituitarism, and permanent DI was observed in $3(6.1 \%)$ patients. One patient (2\%) had cerebrospinal fluid(CSF) leaks treated with serial lumbar punctures. The median follow-up period was 25.45 months; ranged from 3 to 49.

Conclusions: Endoscopic transsphenoidal adenoma resection leads to a high rate of endocrinological remission in patients with low acromegaly complication. Patients with high preoperative GH levels and the Knosp scores are less likely to achieve remission.
\end{abstract}

Keywords: Acromegaly, Endoscopy, Growth Hormone, Pituitary Adenoma, Skull Base

\section{Background}

In most cases acromegaly results from the overproduction of growth hormone (GH) by a pituitary adenoma (1). Excessive secretion of GH and insulin-like growth factor (IGF)-I leads to progressive bone and cartilage growth, cardiovascular, metabolic and respiratory diseases, which contribute to the higher mortality compared with the healthy individuals. Death, in many cases, is caused by cardiovascular or cerebrovascular events. Importantly, the normalization of $\mathrm{GH}$ reduces mortality rates to that of the levels of the general population (2).

Treatment options for acromegaly include surgery, medical therapy, and radiosurgery. Transsphenoidal surgery is the first line treatment for GH-secreting adeno- mas due to its ability to rapidly reduce GH and IGF-I concentrations and lower costs in comparison to other modalities $(3,4)$. Surgical resection alone is sufficient for biochemical control in $75 \%$ to $95 \%$ of microadenomas and $40 \%$ to $68 \%$ of macroadenoma cases (5-8). In case surgery fails to achieve sustainable hormonal remission, medical management with somatostatin analogs, GH receptor antagonist pegvisomant, or dopamine agonist and radiosurgery can be considered as additional treatment options $(9,10)$.

Surgical resection of GH secreting pituitary adenomas is usually done via microscopic and/or endoscopic, transsphenoidal approaches $(11,12)$. Nowadays, the endoscopic transsphenoidal approach is the primary option for the resection of all pituitary adenomas and, in some 
centers, is replaced the traditional microscopic transsphenoidal approach. The endoscopic approach has some advantages including better illumination, improved surgical visualization using angled scopes to reach the parasellar region, less nasal trauma, increased patient comfort, and potentially better results with tumor resection $(3,8)$. In fact, endoscopic endonasal resection of these tumors shows result with equivalent efficacy and safety $(13,14)$ as well as the reduction of time in the operating room and hospital stay $(15,16)$.

Surgical failure is common with macroadenomas invading the cavernous sinuses or extrasellar region $(17,18)$. Recent studies reported some risk factors of lower biochemical remission rate including higher Knosp score and higher preoperative GH and IGF-I levels (19). The goal of acromegaly treatment is to normalize GH and IGF levels by surgical resection alone or in combination with radiosurgery and/or medical therapy. Predicting surgical outcome on the basis of preoperative pituitary magnetic resonance imaging (MRI), GH, and IGF-I levels can be helpful to choose the best treatment protocol.

The previous definition of remission from acromegaly, 2000 consensus criteria, required a normal age- and gender-adjusted IGF-I levels and a nadir GH concentration $>1 \mathrm{ng} / \mathrm{mL}$ during oral glucose tolerance testing (OGTT) (20). However, with the advent of highly sensitive immunoassays, a consensus for more stringent criteria for remission were proposed in 2010 including a normal ageand gender-adjusted IGF-I and random GH levels $<1.0$ $\mathrm{ng} / \mathrm{mL}$ or $\mathrm{GH}$ level $<0.4 \mathrm{ng} / \mathrm{mL}$ during an oral glucose tolerance test (21).

The current study, for the first time in Iran, reported the outcome of endoscopic transsphenoidal surgery to treat 49 cases with GH secreting pituitary adenoma using the 2010 consensus criteria for remission of acromegaly and determine the predictors of remission after surgery in the patients.

\section{Methods}

\subsection{Patient Population}

Data were collected by prospective follow-up of all patients with GH producing pituitary adenomas treated by endoscopic transsphenoidal surgery at Imam Khomeini hospital, Tehran, Iran, from September 2013 to January 2016.

The study was approved by the ethics committee of Tehran University of Medical Sciences. Patients with biochemical assays and clinical diagnosis consistent with acromegaly, and pathological diagnosis consistent with GH-secreting tumor that underwent expanded endoscopic transsphenoidal surgery (EETSS) were included. Exclusion criteria were undergoing medical treatment or previous radiosurgery, contraindications of TSS, contraindications of magnetic resonance imaging (MRI), and adenoma diagnosis not confirm by pathological evaluation. Among the 50 patients, 1 patient was lost to follow-up and excluded from the study. Also, all the patients underwent neurological and endocrinological evaluations including formal visual acuity and field testing before and at least 3 months after the surgery.

\subsection{Radiologic Evaluation}

Radiological evaluation comprised T1-and T2-weighted MR imaging before and after intravenous contrast administration in all patients preoperatively. Tumor size was calculated based on the maximum diameter, and classified as microadenomas ( $\leq 10 \mathrm{~mm}$ ) or macroadenomas $(>10$ $\mathrm{mm}$ ). The suprasellar extension and sellar floor erosion by the tumors were classified according to the Hardy-Wilson classification (Table 1). Cavernous sinus invasion by the tumors was described based on the Knosp classification (22). Postoperative imaging was performed at least 3 months after surgery with 3T MR scanner (Magnetom Verio, Siemens Healthcare, Erlangen, Germany) to evaluate the degree of tumor resection.

Table 1. The Hardy-Wilson Classification

\begin{tabular}{ll}
\hline Stage & Grade \\
\hline o: No suprasellar extension & I: Sella normal; tumor $<10 \mathrm{~mm}$ \\
\hline A: Extention to suprasellar cistern & II: Sella enlarged; tumor $>10 \mathrm{~mm}$ \\
\hline $\begin{array}{l}\text { B: Recesses of third ventricle } \\
\text { oblitered }\end{array}$ & III: Local perforation of sellar floor \\
\hline C: Third ventricle grossly displaced & IV: Diffuse sellar floor destruction \\
\hline D: Intracranial & \\
\hline E: Into/beneath cavernous sinus & \\
\hline
\end{tabular}

\subsection{Surgical Technique}

All patients were operated using the expanded endoscopic transnasal transsphenoidal approach with the aid of neuronavigation guidance (Parsis Co, IRI) by a team consisting of a neurosurgeon and an otolaryngologist.

Sphenoid ostia were visualized and after partial posterior septectomy and entering the sphenoid sinus, sellar floor was exposed from one carotid protuberance to the other, and craniocaudally from the planum sphenoidale to the clivus. In cases where the cavernous sinus was invaded by tumor, a more lateral exposure was achieved by carefully exposing the anterior wall of the cavernous sinus 
up to the lateral aspect of the internal carotid artery (ICA). Then, the dural opening was made from the medial walls of cavernous sinus and from the anterior to the posterior intercavernous sinus. The 3-hand binostril bimanual technique was used to remove the tumor. After tumor resection, multilayered skull base reconstruction was done.

\subsection{Histopathological Evaluation}

Pathologists examined the surgical specimens histologically in all patients to confirm pituitary adenoma diagnosis. The tumor specimens were stained by hematoxylin and eosin (H\&E) for routine examination.

\subsection{Endocrine Analysis}

Serum GH, IGF-I, prolactin, random cortisol, T3, free T4, thyrotropin (TSH), follicle- stimulating (FSH), luteinizing (LH) hormones, and serum testosterone were assessed preoperatively. All patients underwent postoperative evaluation of GH/IGF-I levels as well as anterior pituitary function at 3, 6, 9, 12, 18, 24, and 36 months after the surgery. OGTT was performed in the first postoperative follow-up evaluation. Appropriate hormone replacement therapy was administered to patients with clinical and laboratory signs and symptoms of hypopituitarism. Biochemical remission, based on 2010 consensus guidelines (21), was achieved if their age- and gender-adjusted IGF-I level was within the normal range with either a random $\mathrm{GH}<1$ $\mathrm{ng} / \mathrm{mL}$ or a nadir $\mathrm{GH}<0.4 \mathrm{ng} / \mathrm{mL}$ following an OGTT on the last follow-up date at least 3 months after surgery. If either GH or IGF-I level was not in the cure range, the patient was considered as discordant or failed to attain remission.

\subsection{Statistical Analysis}

The Statistical Package for Social Sciences (SPSS version 17.0, Chicago, IL) was used for data analysis. Baseline and postoperative values were presented as mean \pm standard deviation (SD) for continuous variables and frequency for categorical data. Categorical variables were analyzed with the Chi-square or the Fisher exact test, and means of continuous variables were analyzed with the Student $t$ test and ANOVA followed by the Bonferroni post hoc test. ROC curve was used to determine the sensitivity and specificity of the cutoff points, and the area under the curve (AUC) and 95\% confidence intervals (CIs) were also calculated. Statistical significance was defined by a P value of $<0.05$.

\section{Results}

\subsection{Patient Characteristics}

Of the 49 recruited patients, 22 were female and 27 male with the mean age of 39.7 years; ranged 12 to 66 ).
Three patients had recurrent adenomas and also 3 other cases referred to the center as residual adenomas after microscopic transnasal surgery. The mean follow-up period was 25.4 months; ranged 3 to 49.

Five patients (10.2\%) presented with visual field defects as demonstrated by preoperative formal visual field testing and all of them experienced an improvement postoperatively. No patient experienced a decrease in visual field or acuity postoperatively. Gonadal deficiency was the most common preoperative endocrine deficiency in 19 patients (38.8\%). Five patients (10.2\%) had clinical and pathological features of mixed prolactin and GH secreting adenoma.

The mean preoperative serum IGF-I level was $816.38 \pm$ $262.63 \mathrm{ng} / \mathrm{mL}$, ranged 250 to 1500 , and the mean preoperative random $\mathrm{GH}$ was measured as $26.13 \pm 24.46 \mathrm{ng} / \mathrm{mL}$; ranged 1.6 to 150 .

\subsection{Tumor Characteristics}

All pituitary adenomas were analyzed based on preoperative MRI findings. Overall, the mean \pm SD of adenoma sizes was $18.8 \pm 9.5 \mathrm{~mm}$; ranged 2.5 to 43 . Nine patients (18.4\%) had microadenomas and 40 patients (81.6\%) macroadenomas. According to the Knosp classification, based on the coronal T1-weighted images with contrast injection, there were thirty-one cases (63.3\%) with Knosp grade 0 and 1, as well as eleven (22.4\%) with Knosp grade 2, five (10.2\%) Knosp grade 3, and two (4.1\%) Knosp grade 4. The Hardy-Wilson classification was used to indicate the degree of suprasellar/parasellar extension and sellar floor erosion. For suprasellar and parasellar extension, nineteen (38.8\%) patients were stage 0 , ten $(20.4 \%)$ with stage A, two (4.1\%) with stage B, and eighteen (36.7\%) with stage E. For sellar floor destruction, ten patients (20.4\%) were Grade I, twenty-three (46.9\%) Grade II, six (12.2\%) Grade III, and ten (20.4\%) cases were classified as Grade IV. Preoperative characteristics of patients and tumors are also summarized in Table 2.

\subsection{Surgical Outcome and Remission}

Gross and near total resections were achieved in 45 (91.8\%) and 4 (8.2\%) patients, respectively.

Based on 2010 criteria, the overall rate of remission at 3 months after surgery was $69.4 \%$ (34 patients). Six patients (12.2\%) with discordant values were followed up closely. Among 4 patients with normal IGF-I and elevated GH values, 1 patient met remission criteria and 1 patient had elevated IGF-I level in the last follow-up. Also, of 2 patients with normal GH and high IGF-I levels, 1 patient achieved remission in the last follow-up. The overall rate of biochemical remission at the last follow-up in the current case series was 71.4\% (35 of 49 patients). From 6 patients 
Table 2. Preoperative Characteristics of Patients with Acromegaly ${ }^{a}$

\begin{tabular}{|c|c|}
\hline Variables & Value \\
\hline \multicolumn{2}{|l|}{ Gender } \\
\hline Female & $22(44.9)$ \\
\hline Male & $27(55.1)$ \\
\hline Age, $y$ & $39.71 \pm 11.39(12-66)$ \\
\hline \multicolumn{2}{|l|}{ Size } \\
\hline Microadenoma & $9(18.4)$ \\
\hline Macroadenoma & $40(81.6)$ \\
\hline Size, $\mathbf{m m}$ & $18.81 \pm 9.48(2.5-43)$ \\
\hline Preoperative GH, $\mu / \mathbf{d L}$ & $26.13 \pm 24.46(1.6-150)$ \\
\hline Preoperative IGF - I, ng/mL & $816.38 \pm 262.63(250-1500)$ \\
\hline \multicolumn{2}{|l|}{ Type } \\
\hline Primary & $43(87.8)$ \\
\hline Residual & $3(6.1)$ \\
\hline Recurrence & $3(6.1)$ \\
\hline \multicolumn{2}{|l|}{ Visual field deficit } \\
\hline No & $44(89.8)$ \\
\hline Yes & $5(10.2)$ \\
\hline \multicolumn{2}{|l|}{ The Knosp score } \\
\hline I & $31(63.3)$ \\
\hline II & $11(22.4)$ \\
\hline III & $5(10.2)$ \\
\hline IV & $2(4.1)$ \\
\hline \multicolumn{2}{|l|}{ The Hardy-Wilson grade } \\
\hline I & $10(20.4)$ \\
\hline II & $23(46.9)$ \\
\hline III & $6(12.2)$ \\
\hline IV & $10(20.4)$ \\
\hline \multicolumn{2}{|l|}{ The Hardy-Wilson stage } \\
\hline 0 & $19(38.8)$ \\
\hline A & $10(20.4)$ \\
\hline $\mathrm{B}$ & $2(4.1)$ \\
\hline E & $18(36.7)$ \\
\hline \multicolumn{2}{|c|}{ Preoperative hormonal deficit } \\
\hline Testosterone deficit & $15(30.6)$ \\
\hline LH deficit & $4(8.2)$ \\
\hline Follow - up duration, mo & $25.45 \pm 8.73(3-49)$ \\
\hline
\end{tabular}

(12.1\%) with recurrent or residual tumors after a failed microscopic transsphenoidal resection by other surgeons, 4 subjects met the criteria for remission after EETSS.

Final remission was established in $77.8 \%$ ( 7 out of 9 ) of microadenomas and $70 \%$ (28 out of 40 ) of macroadenomas. A comparison of remission rates for microadenomas versus macroadenomas showed no statistically significant difference. However, patients who achieved remission had smaller tumor diameter compared to the patients who did not, but the difference was insignificant (18.31 mm vs. 21.41 $\mathrm{mm})$.

In comparison with the overall remission rate of $71.4 \%$ using the 2010 criteria, remission was achieved in 39 of $49(79.6 \%)$ patients according to the prior guidelines published in 2000 (Table 3).

\subsection{Preoperative Prediction of Remission}

According to the current study, age, gender, tumor size, and history of previous surgery did not affect the remission rates $(\mathrm{P}>0.05)$. Remission rates were statistically similar in microadenomas and macroadenomas $(77.8 \%$ vs. $70 \%$; $\mathrm{P}>0.05$ ). In patients who achieved remission, basal GH levels were significantly lower, compared with that of the unremitted group. However, basal IGF-I levels were similar in both groups.

The suprasellar/parasellar extension and sphenoid sinus invasion by the tumors were classified based on the Hardy-Wilson classification. No significant difference was observed in remission rates between the various grades and stages $(P>0.05)$. However, in the Knosp classification, based on cavernous sinus invasion, remission rates decrease significantly in the higher grades (III and IV) (Table 4). The cutoff preoperative GH level to predict the remission was $22.5 \mu \mathrm{g} / \mathrm{dL}$; with $63.6 \%$ sensitivity and $63.2 \%$ specificity for remission (AUC 0.636; 95\% CI: 0.409 to 0.863 ).

\subsection{Complications}

There were no major complications. Two patients (4.1\%) developed panhypopituitarism. Transient postoperative diabetes insipidus was observed in 11 (22.4\%) patients, which was treated medically with desmopressin. Permanent diabetes insipidus (DI) was observed in 3 (6.1\%) patients.

Of the 15 males with preoperative testosterone deficiency undergoing surgery, 8 (53.3\%) cases improved. Also, among 4 female patients with preoperative luteinizing hormone (LH) deficiency, 3 (75\%) cases regained normal function.

All patients with preoperative visual deficits experienced improvement in their vision, and no patient had a new visual deficit. Postoperative CSF leak occurred in 1 patient after resection of a macroadenoma, which was resolved with serial lumbar punctures. No surgery-related deaths or meningitis were observed. 
Table 3. Remission Rate Using 2000 and 2010 Consensus $^{\mathrm{a}}$

\begin{tabular}{|c|c|c|c|c|c|c|}
\hline \multirow[t]{2}{*}{ Variables } & \multicolumn{3}{|c|}{2000 Criteria } & \multicolumn{3}{|c|}{2010 Criteria } \\
\hline & Yes & Discordance & No & Yes & Discordance & No \\
\hline \multicolumn{7}{|c|}{ Remission Rate at 3 Months } \\
\hline Microadenoma & $8(88.9)$ & $1(11.1)$ & 0 & $8(88.9)$ & $1(11.1)$ & 0 \\
\hline Macroadenoma & $31(77.5)$ & $2(5.0)$ & $7(17.5)$ & $26(65.0)$ & $5(12.5)$ & $9(22.5)$ \\
\hline Overall & $39(79.6)$ & $3(6.1)$ & $7(14.3)$ & $34(69.4)$ & $6(12.2)$ & $9(18.4)$ \\
\hline \multicolumn{7}{|c|}{ Remission Rate at Last Follow-up } \\
\hline Microadenoma & $8(88.9)$ & 0 & $1(11.1)$ & $7(77.8)$ & $1(11.1)$ & $1(11.1)$ \\
\hline Macroadenoma & $31(77.5)$ & $2(5.0)$ & $7(17.5)$ & $28(70.0)$ & $2(5.0)$ & $10(25.0)$ \\
\hline Overall & $39(79.6)$ & $2(4.1)$ & $8(16.3)$ & $35(71.4)$ & $3(6.1)$ & $11(22.5)$ \\
\hline
\end{tabular}

${ }^{\mathrm{a}}$ Values are expressed as No. (\%).

Table 4. Statistical Analysis of Categorical and Continuous Variables for Patients Treated by Endoscopic Approach ${ }^{\mathrm{a}}$

\begin{tabular}{|c|c|c|c|c|}
\hline Variable & Remission & & & PValue \\
\hline & Yes & Discordance & No & \\
\hline Age, y & $41.00 \pm 9.91$ & $51.00 \pm 8.18$ & $32.55 \pm 13.25$ & 0.079 \\
\hline Size, $\mathbf{m m}$ & $18.31 \pm 9.75$ & $15.00 \pm 6.24$ & $21.41 \pm 9.33$ & 0.504 \\
\hline Pre-op GH, $\mu /$ dL & $21.48 \pm 18.38$ & $17.77 \pm 11.01$ & $43.23 \pm 42.07$ & 0.047 \\
\hline Pre-op IGF1, ng/mL & $\begin{array}{c}833.10 \pm \\
250.70\end{array}$ & $\begin{array}{c}480.67 \pm \\
237.25\end{array}$ & $\begin{array}{c}854.73 \pm \\
264.04\end{array}$ & 0.069 \\
\hline Microadenoma & $7(77.8)$ & $1(11.1)$ & 1 (11.1) & 0.565 \\
\hline Macroadenoma & $28(70)$ & $2(5)$ & $10(25)$ & \\
\hline Female & $16(72.7)$ & $2(9.1)$ & $4(18.2)$ & 0.635 \\
\hline Male & $19(70.4)$ & $1(3.7)$ & $7(25.9)$ & \\
\hline Primary & $31(72.1)$ & $2(4.7)$ & $10(23.3)$ & \multirow{2}{*}{0.505} \\
\hline Recurrence/residue & $4(66.7)$ & $1(16.7)$ & $1(16.7)$ & \\
\hline The Knosp I & $22(71.0)$ & $2(6.5)$ & $7(22.6)$ & \multirow{4}{*}{0.041} \\
\hline The Knosp II & $10(90.9)$ & 0 & $1(9.1)$ & \\
\hline The Knosp III & $2(40.0)$ & 0 & $3(60.0)$ & \\
\hline The Knosp IV & $1(50.0)$ & $1(50.0)$ & o( & \\
\hline The Hardy grade I & $8(80.0)$ & $1(10.0)$ & $1(10.0)$ & \multirow{4}{*}{0.810} \\
\hline The Hardy grade II & $15(65.2)$ & $2(8.7)$ & $6(26.1)$ & \\
\hline The Hardy grade III & $5(83.3)$ & 0 & $1(16.7)$ & \\
\hline The Hardy grade IV & $7(70.0)$ & 0 & $3(30.0)$ & \\
\hline The Hardy stage 0 & $14(73.7)$ & $2(10.5)$ & $3(15.8)$ & \multirow{4}{*}{0.165} \\
\hline The Hardy stage A & $7(70.0)$ & 0 & $3(30.0)$ & \\
\hline The Hardy stage B & 0 & 0 & $2(100)$ & \\
\hline The Hardy stage E & $14(77.8)$ & $1(5.6)$ & $3(16.7)$ & \\
\hline Gross total resection & $35(77.8)$ & $3(6.7)$ & $7(15.6)$ & \multirow{2}{*}{0.001} \\
\hline Near total resection & 0 & 0 & $4(100)$ & \\
\hline
\end{tabular}

\section{Discussion}

The main goal of the surgical treatment in patients with acromegaly is to reduce the rate of morbidity and mortality to the normal rates in the general population, by managing the tumor growth and lowering the GH and IGFI levels $(17,23)$.

Better visualization and improvement in the resection of suprasellar and parasellar components of the adenoma with the development of expanded endoscopic transsphenoidal surgery are associated with better results (24). The current study presented the results of biochemical remission, short-term outcome, and the predictive factors of endocrinological remission in a series of 49 patients with acromegaly who underwent expanded endoscopic transsphenoidal pituitary surgeries.

Over the past decades, the definition of biochemical remission of acromegaly changed noticeably. The 2000 consensus criteria, defined remission as normal age- and gender-adjusted IGF-I level and a random GH value $>2.5$ $\mathrm{ng} / \mathrm{mL}$ or GH value $>1 \mathrm{ng} / \mathrm{mL}$ during an OGTT test (20). However; mortality rates remained high with these $\mathrm{GH}$ and IGF-I levels (25). Therefore, with the recent development of highly sensitive and specific GH assays, more stringent criteria to define the biochemical remission of acromegaly are proposed. Recent 2010 consensus described remission as a random $\mathrm{GH}<1 \mathrm{ng} / \mathrm{mL}$ or nadir $\mathrm{GH}$ levels $<$ $0.4 \mathrm{ng} / \mathrm{mL}$ with OGTT and IGF-I levels within an age- and gender-adjusted normal range (21). The current study used more stringent 2010 consensus criteria to describe the endocrinological remission of patients with acromegaly.

Several previous reports on microscopic or endoscopic resection of GH secreting pituitary adenomas used different criteria to define biochemical remission; thus, they cannot be directly compared to the current study results. In the current study, reanalyzing data, applying 2000 criteria, led to $8.2 \%$ higher remission rate (Table 3 ).

Currently, there are a few published endoscopic stud- 
ies using the 2010 criteria with the reported remission rates of $28.8 \%$ to $70.8 \%(7,19,26-33)$. The current study results showed an overall remission rate of $71.4 \%$ with the mean follow-up of 25.4 months. The current study used the minimum time of 3 months, since it was previously shown that postoperative IGF-I levels fluctuate and only stabilize at 3 months (34). The remission rate of the current study was comparable to other endoscopic results using the 2010 criteria (Table 5).

Several studies, similar to the current study result, reported that preoperative GH levels predicted remission using 2010 consensus criteria $(19,27,28)$. Various preoperative GH levels were predictive. Sarkar et al., and Starke et al., showed that a preoperative $\mathrm{GH}$ level $<40 \mathrm{ng} / \mathrm{mL}$ and $\mathrm{GH}<$ $45 \mathrm{ng} / \mathrm{mL}$ were associated with higher rates of remission, respectively $(27,28)$.

In the current study, microadenomas had higher biochemical remission rates than macroadenomas $(77.8 \%$ vs. $70 \%$; but the difference was not significant. In contrast to earlier publications, tumor size was not an important predictive factor for remission in the current study $(19,32,33)$. Sarkar et al., revealed that an adenoma size $<20 \mathrm{~mm}$ was the predictor of outcome at follow-up (27).

According to the Hardy-Wilson classification, there was no significant difference in remission rate among different stages or grades. This finding showed that suprasellar extension or sphenoid sinus invasions did not affect the success of endoscopic transsphenoidal surgery. Recent studies stated that the Hardy-Wilson grades and stages were the predictive values in achieving remission. Similar to the current study, Yildirim et al., reported that suprasellar extension did not affect the remission rate. However, cavernous sinus invasion and sphenoid sinus invasion were associated with lower rates of disease control (30). Shin et al., showed that the Hardy stages C, D, and E were predictive against remission after endoscopic approach, albeit, no difference in remission were found between the Hardy grades (32). As described earlier in the current study, $36.7 \%$ of the cases were classified as the Hardy-Wilson stage $\mathrm{E}$ (cavernous sinus invasion) with remission rate of $77.8 \%$, which was considerably higher than reported in the literature. However, in the current study series, adenoma size and the Hardy grades and stages had no effect on achieving remission. Endoscopes enhance the visualization of the lateral and suprasellar extent of larger tumors; thus, suprasellar compartment and lateral extensions of tumor may be more accessible to the surgeon under direct vision (35). In the current study, the extended approach significantly helped to explore the wall of the cavernous sinus directly and resect tumor extensions.

The current study analyzed the rate of remission according to the Knosp classification. In grade 0, 1, and
2 groups, there were 42 patients out of which 32 (76.2\%) achieved remission. In grade 3 and 4 groups, there were 7 patients out of which 3 (42.9\%) achieved remission. Although cavernous sinus involvement (the Hardy-Wilson stage E) did not solely affect the surgical outcome, these findings showed that the Knosp grade and degree of cavernous sinus involvement was an important predictive factor for hormonal remission. Higher degree of cavernous sinus invasion (the Knosp grades III and IV) associated with lower rate of remission. This finding was in accordance with those of the earlier studies $(19,28,30,32)$. Due to the importance of the Knosp grade, careful preoperative review of MRI is necessary for surgical planning and the extent of resection (36). Because of the better illumination, direct visualization, and by use of an angled endoscope, the endoscopic technique seemed superior to microscopic techniques to treat adenomas with cavernous sinus invasion (37).

Age, gender, primary or secondary surgery, and basal IGF-I levels had no effect on achieving a remission (Table 4).

Among 6 patients with discordant IGF-I and OGTT results at 3 months of follow-up, 2 patients achieved remission and 1 did not. Discordance rate was $6.1 \%$ (3 of 49 patients) in the last follow-up. Various studies obtained different discordance rates. In the endoscopic series, discordant values were observed in $11.5 \%$ to $35 \%$ of the patients $(19,27,28,31)$. Despite the use of current sensitive assays and more stringent criteria to define remission, the rate of discordance still remains high. Several mechanisms are proposed to explain the postoperative discordance of $\mathrm{GH}$ and IGF-I including altered dynamics of the GH secretion after surgery, early postoperative hormone assay, GH nadir values not adjusted to age, gender, body mass index (BMI), the influence of concomitant medication, and co-existing physiologic, and pathologic conditions (38).

One of the limitations of the presented series was the relatively small number of patients that may lead to failure to detect significant differences in outcomes. There were no cases classified as the Hardy stages $C$ and D. Additionally, a long-term follow-up is necessary to determine the rates of remission and the growing experience of the surgeon may affect the outcomes and the rate of complications. Also, the role of pathobiological markers such as p53 and Ki 67 on the long-term outcome of growth hormone-secreting pituitary adenomas should be considered (39).

\subsection{Conclusion}

The current study results demonstrated that the expanded endoscopic transsphenoidal approach to the resection of GH-secreting pituitary adenomas led to biochemical remission in $71.4 \%$ of patients, based on the 2010 criteria. Endoscopic technique facilitated the resection of 
Table 5. Overview of the Results of Published Endoscopic Surgery Using 2010 Consensus Criteria

\begin{tabular}{|c|c|c|c|c|}
\hline First Author & Year of Publication & Number of Patients & Remission Rate, \% & Follow-up Duration, mo \\
\hline Xie & 2016 & 43 & 69.8 & 3-12 \\
\hline Fathalla & 2015 & 42 & 45.2 & 66.1 \\
\hline Sarkar & 2014 & 66 & 28.8 & 22.4 \\
\hline Yildirim & 2014 & 56 & 66.1 & 6 \\
\hline Fathalla & 2014 & 20 & 35 & 11 \\
\hline Starke & 2013 & 72 & 70.8 & 18.4 \\
\hline Shin & 2013 & 53 & 50.9 & 30 \\
\hline Hazer & 2013 & 214 & 64.5 & 12 \\
\hline Wang & 2012 & 43 & 67.0 & 34 \\
\hline Jane & 2011 & 60 & 69.7 & 21.8 \\
\hline Hofstetter & 2010 & 24 & 46 & 23 \\
\hline
\end{tabular}

suprasellar tumor extensions. It was observed that the lower preoperative GH and the Knosp scores significantly associated with achieving the higher rate of remission.

\section{Footnotes}

Authors' Contribution: Mehdi Zeinalizadeh and Seyed Mousa Sadrehosseini, study concept, design, and supervision; Mohammad Taghvaei and Seyed Mojtaba Miri, data acquisition and drafting the manuscript.

Financial Disclosure: Authors declared no financial interest related to the material in the study.

Conflict of Interests: Authors declared no conflict of interest.

Funding/Support: The study had no financial support.

\section{References}

1. Chanson P, Salenave S, Kamenicky P, Cazabat L, Young J. Pituitary tumours: acromegaly. Best Pract Res Clin Endocrinol Metab. 2009;23(5):555-74. doi: 10.1016/j.beem.2009.05.010. [PubMed: 19945023].

2. Dekkers OM, Biermasz NR, Pereira AM, Romijn JA, Vandenbroucke JP. Mortality in acromegaly: a metaanalysis. J Clin Endocrinol Metab. 2008;93(1):61-7. doi: 10.1210/jc.2007-1191. [PubMed:17971431].

3. Gondim JA, Ferraz T, Mota I, Studart D, Almeida JP, Gomes E, et al. Outcome of surgical intrasellar growth hormone tumor performed by a pituitary specialist surgeon in a developing country. Surg Neurol. 2009;72(1):15-9. doi: 10.1016/j.surneu.2008.02.012. [PubMed: 18440607] discussion 19.

4. Esposito V, Santoro A, Minniti G, Salvati M, Innocenzi G, Lanzetta G, et al. Transsphenoidal adenomectomy for GH-, PRL-and ACTH-secreting pituitary tumours: outcome analysis in a series of 125 patients. Neurol Sci. 2004;25(5):251-6. doi: 10.1007/s10072-004-0351-z. [PubMed: $15624082]$.

5. Ahmed S, Elsheikh M, Stratton IM, Page RC, Adams CB, Wass JA. Outcome of transphenoidal surgery for acromegaly and its relationship to surgical experience. Clin Endocrinol (Oxf). 1999;50(5):561-7. doi: 10.1046/j.1365-2265.1999.00760.x. [PubMed:10468920].

6. Freda PU, Wardlaw SL, Post KD. Long-term endocrinological follow-up evaluation in 115 patients who underwent transsphenoidal surgery for acromegaly. J Neurosurg. 1998;89(3):353-8. doi: 10.3171/jns.1998.89.3.0353. [PubMed: 9724106].

7. Hofstetter CP, Mannaa RH, Mubita L, Anand VK, Kennedy JW, Dehdashti AR, et al. Endoscopic endonasal transsphenoidal surgery for growth hormone-secreting pituitary adenomas. Neurosurg Focus. 2010;29(4):E6. doi: 10.3171/2010.7.FOCUS10173. [PubMed: 20887131].

8. Tabaee A, Anand VK, Barron Y, Hiltzik DH, Brown SM, Kacker A, et al. Endoscopic pituitary surgery: a systematic review and meta-analysis. J Neurosurg. 2009;111(3):545-54. doi: 10.3171/2007.12.17635. [PubMed: 19199461].

9. Sherlock M, Woods C, Sheppard MC. Medical therapy in acromegaly. Nat Rev Endocrinol. 2011;7(5):291-300. doi: 10.1038/nrendo.2011.42. [PubMed: 21448141].

10. Castinetti F, Regis J, Dufour H, Brue T. Role of stereotactic radiosurgery in the management of pituitary adenomas. Nat Rev Endocrinol. 2010;6(4):214-23. doi: 10.1038/nrendo.2010.4. [PubMed: 20177403].

11. Abosch A, Tyrrell JB, Lamborn KR, Hannegan LT, Applebury CB, Wilson CB. Transsphenoidal microsurgery for growth hormonesecreting pituitary adenomas: initial outcome and long-term results. J Clin Endocrinol Metab. 1998;83(10):3411-8. doi: 10.1210/jcem.83.10.5111. [PubMed: 9768640].

12. Shimon I, Cohen ZR, Ram Z, Hadani M. Transsphenoidal surgery for acromegaly: endocrinological follow-up of 98 patients. Neurosurgery. 2001;48(6):1239-43. doi: 10.1227/00006123-20010600000008. [PubMed: 11383725] discussion 1244-5.

13. Rudnik A, Zawadzki T, Wojtacha M, Bazowski P, Gamrot J, GaluszkaIgnasiak B, et al. Endoscopic transnasal transsphenoidal treatment of pathology of the sellar region. Minim Invasive Neurosurg. 2005;48(2):101-7. doi:10.1055/s-2004-830185. [PubMed:15906205].

14. Frank G, Pasquini E, Farneti G, Mazzatenta D, Sciarretta V, Grasso $\mathrm{V}$, et al. The endoscopic versus the traditional approach in pituitary surgery. Neuroendocrinology. 2006;83(3-4):240-8. doi: 10.1159/000095534. [PubMed: 17047389].

15. Higgins TS, Courtemanche C, Karakla D, Strasnick B, Singh RV, Koen JL, et al. Analysis of transnasal endoscopic versus transseptal microscopic approach for excision of pituitary tumors. Am J Rhinol. 2008;22(6):649-52. doi: 10.2500/ajr.2008.22.3246. [PubMed: 19178807]. 
16. Schaberg MR, Anand VK, Schwartz TH, Cobb W. Microscopic versus endoscopic transnasal pituitary surgery. Curr Opin Otolaryngol Head Neck Surg. 2010;18(1):8-14. doi: 10.1097/MOO.ob013e328334db5b. [PubMed: 19966567].

17. Campbell PG, Kenning E, Andrews DW, Yadla S, Rosen M, Evans JJ. Outcomes after a purely endoscopic transsphenoidal resection of growth hormone-secreting pituitary adenomas. Neurosurg Focus. 2010;29(4):E5. doi: 10.3171/2010.7.FOCUS10153. [PubMed: 20887130].

18. Besser GM, Burman P, Daly AF. Predictors and rates of treatmentresistant tumor growth in acromegaly. Eur $J$ Endocrinol. 2005;153(2):187-93. doi: 10.1530/eje.1.01968. [PubMed: 16061822].

19. Jane JJ, Starke RM, Elzoghby MA, Reames DL, Payne SC, Thorner MO, et al. Endoscopic transsphenoidal surgery for acromegaly: remission using modern criteria, complications, and predictors of outcome. J Clin Endocrinol Metab. 2011;96(9):2732-40. doi: 10.1210/jc.2011-0554. [PubMed: 21715544].

20. Giustina A, Barkan A, Casanueva FF, Cavagnini F, Frohman L, Ho $\mathrm{K}$, et al. Criteria for cure of acromegaly: a consensus statement. $J$ Clin Endocrinol Metab. 2000;85(2):526-9. doi: 10.1210/jcem.85.2.6363. [PubMed: 10690849].

21. Giustina A, Chanson P, Bronstein MD, Klibanski A, Lamberts S, Casanueva FF, et al. A consensus on criteria for cure of acromegaly. J Clin Endocrinol Metab. 2010;95(7):3141-8. doi: 10.1210/jc.2009-2670. [PubMed: 20410227].

22. Knosp E, Steiner E, Kitz K, Matula C. Pituitary adenomas with invasion of the cavernous sinus space: a magnetic resonance imaging classification compared with surgical findings. Neurosurgery. 1993;33(4):6107. doi: 10.1227/00006123-199310000-00008. [PubMed: 8232800] discussion 617-8.

23. Swearingen B, Barker F2, Katznelson L, Biller BM, Grinspoon S, Klibanski A, et al. Long-term mortality after transsphenoidal surgery and adjunctive therapy for acromegaly. J Clin Endocrinol Metab. 1998;83(10):3419-26. doi: 10.1210/jcem.83.10.5222. [PubMed: 9768641].

24. Gondim JA, Schops M, de Almeida JP, de Albuquerque LA, Gomes E, Ferraz T, et al. Endoscopic endonasal transsphenoidal surgery: surgical results of 228 pituitary adenomas treated in a pituitary center. Pituitary. 2010;13(1):68-77. doi: 10.1007/s11102-009-0195-x. [PubMed: 19697135].

25. Beauregard C, Truong U, Hardy J, Serri O. Long-term outcome and mortality after transsphenoidal adenomectomy for acromegaly. Clin Endocrinol (Oxf). 2003;58(1):86-91. doi: 10.1046/j.13652265.2003.01679.x. [PubMed: 12519417].

26. Fathalla H, Cusimano MD, Di Ieva A, Lee J, Alsharif O, Goguen J, et al. Endoscopic versus microscopic approach for surgical treatment of acromegaly. Neurosurg Rev. 2015;38(3):541-8. doi: 10.1007/s10143-0150613-7. [PubMed: 25666392] discussion 548-9.

27. Sarkar S, Rajaratnam S, Chacko G, Chacko AG. Endocrinological outcomes following endoscopic and microscopic transsphenoidal surgery in 113 patients with acromegaly. Clin Neurol Neurosurg. 2014;126:190-5. doi: 10.1016/j.clineuro.2014.09.004. [PubMed: 25278017].

28. Starke RM, Raper DM, Payne SC, Vance ML, Oldfield EH, Jane JJ. Endoscopic vs microsurgical transsphenoidal surgery for acromegaly: out- comes in a concurrent series of patients using modern criteria for remission.JClin Endocrinol Metab. 2013;98(8):3190-8. doi:10.1210/jc.20131036. [PubMed: 23737543].

29. Xie T, Liu T, Zhang X, Chen L, Luo R, Sun W, et al. Time to Revive the Value of the Pseudocapsule in Endoscopic Endonasal Transsphenoidal Surgery for Growth Hormone Adenomas. World Neurosurg. 2016;89:65-71. doi: 10.1016/j.wneu.2016.01.036. [PubMed: 26805694].

30. Yildirim AE, Sahinoglu M, Divanlioglu D, Alagoz F, Gurcay AG, Daglioglu E, et al. Endoscopic endonasal transsphenoidal treatment for acromegaly: 2010 consensus criteria for remission and predictors of outcomes. Turk Neurosurg. 2014;24(6):906-12. doi: 10.5137/10195149.JTN.11288-14.1. [PubMed: 25448208].

31. Fathalla H, Cusimano MD, Alsharif OM, Jing R. Endoscopic transphenoidal surgery for acromegaly improves quality of life. Can J Neurol Sci. 2014;41(6):735-41. doi: 10.1017/cjn.2014.106. [PubMed: 25431207].

32. Shin SS, Tormenti MJ, Paluzzi A, Rothfus WE, Chang YF, Zainah $\mathrm{H}$, et al Endoscopic endonasal approach for growth hormone secreting pituitary adenomas: outcomes in 53 patients using 2010 consensus criteria for remission. Pituitary. 2013;16(4):435-44. doi: 10.1007/s11102-0120440-6. [PubMed: 23179961].

33. Hazer DB, Isik S, Berker D, Guler S, Gurlek A, Yucel T, et al. Treatment of acromegaly by endoscopic transsphenoidal surgery: surgical experience in 214 cases and cure rates according to current consensus criteria. J Neurosurg. 2013;119(6):1467-77. doi: 10.3171/2013.8.JNS13224. [PubMed: 24074496].

34. Bates AS, Evans AJ, Jones P, Clayton RN. Assessment of GH status in acromegaly using serum growth hormone, serum insulin-like growth factor-1 and urinary growth hormone excretion. Clin Endocrinol (Oxf). 1995;42(4):417-23. doi: 10.1111/j.13652265.1995.tb02652.x. [PubMed: 7750196].

35. McLaughlin N, Eisenberg AA, Cohan P, Chaloner CB, Kelly DF. Value of endoscopy for maximizing tumor removal in endonasal transsphenoidal pituitary adenoma surgery.J Neurosurg. 2013;118(3):613-20. doi: 10.3171/2012.11.JNS112020. [PubMed: 23240699].

36. Marquez Y, Tuchman A, Zada G. Surgery and radiosurgery for acromegaly: a review of indications, operative techniques, outcomes, and complications. Int J Endocrinol. 2012;2012:386401. doi: 10.1155/2012/386401. [PubMed: 22518121].

37. Ceylan S, Koc K, Anik I. Endoscopic endonasal transsphenoidal ap proach for pituitary adenomas invading the cavernous sinus. J Neurosurg. 2010;112(1):99-107. doi: 10.3171/2009.4.JNS09182. [PubMed: 19480546].

38. Zeinalizadeh M, Habibi Z, Fernandez-Miranda JC, Gardner PA, Hodak SP, Challinor SM. Discordance between growth hormone and insulin-like growth factor-1 after pituitary surgery for acromegaly: a stepwise approach and management. Pituitary. 2015;18(1):48-59. doi: 10.1007/s11102-014-0556-y. [PubMed: 24496953].

39. Alimohamadi M, Ownagh V, Mahouzi L, Ostovar A, Abbassioun K, Amirjmshidi A. The impact of immunohistochemical markers of Ki67 and p53 on the long-term outcome of growth hormone-secreting pituitary adenomas: A cohort study. Asian J Neurosurg. 2014;9(3):1306. doi: 10.4103/1793-5482.142732. [PubMed: 25685203]. 